\title{
Chikungunya virus; Review of Epidemiology and Outbreak in Pakistan
}

\author{
Tousif Raza*1, Habiba Ijaz², Naseer Ahmad ${ }^{3}$, Muhammad Hashim Raza $^{4}$ \\ ${ }^{1}$ Rawalpindi Medical College, Rawalpindi, Pakistan, 46000 \\ ${ }^{2}$ Benazir Bhutto Hospital, Rawalpindi, Pakistan, 46000 \\ ${ }^{3}$ Departments of Cardiovascular Sciences, University of Verona, Italy, 37126 \\ ${ }^{4}$ Department of Bioinformatics and Biotechnology, International Islamic University, Islamabad, Pakistan, 44000
}

\begin{tabular}{l} 
A R T I C L E I N F O \\
\hline Article history: \\
Received: 16 March, 2017 \\
Accepted: 23 April, 2017 \\
Online: 02 May, 2017
\end{tabular}

Keywords:

Chikungunya Virus

CHIKV

Chikungunya in Pakistan

\begin{abstract}
A B S T R A C T
Chikungunya virus (CHIKV) is mosquito-borne, alpha virus. It causes acute fever and acute and chronic musculoskeletal pain in humans. CHIKV has spread to 22 countries including Pakistan resulting in hundreds of thousands of death across the world. International travel stands out as one of the major risk factors for rapid global spread of the disease. CHIKV can be highly debilitating and large epidemic have severe economic consequences. Reemergence of CHIKV is serious public health concern. In the past 10 years, after decades of infrequent, specific outbreaks, the virus has caused major epidemic outbreaks in Africa, Asia, the India Ocean, and more recently the Caribbean and Americas. Chikungunya virus represents a substantial health burden to affected population, with symptoms that include severe joint and muscle pain, rashes, and fever, as well as prolonged periods of disability in some patients. Entry of virus into tissues causes infiltration of innate immune cells, monocytes, macrophages, neutrophils, natural killer cells and adaptive immune cells. Macrophages bearing the replicating virus, in turn, secrete pro-inflammatory cytokines IL1B, TNF-a, IL-17. Together, this pro-inflammatory milieu induces osteoclastogenesis, bone loss, and erosion. Understanding the mechanisms of host immune responses is essential for the development of diagnosis, treatments and vaccines. Viral culture and isolation from blood cells of infected patients are the Gold standards for diagnosis. Early diagnosis of CHIKV is possible by nucleic acid detection techniques. Thus there is urgent need for continued research into the epidemiology, pathology, prevention and treatment of this disease. In this article, we have provided and update on Chikungunya virus with its recent epidemiology, molecular virology and antiviral therapies and vaccines.
\end{abstract}

\section{Introduction}

Chikungunya virus (CHIKV) is mosquito-borne, alpha virus. It causes acute fever and acute and chronic musculoskeletal pain in humans. CHIKV has spread to 22 countries including Pakistan resulting in hundreds of thousands of death across the world. International travel stands out as one of the major risk factors for rapid global spread of the disease. $(1,2)$ CHIKV can be highly debilitating and large epidemic have severe economic consequences. Re-emergence of Chikungunya virus is of serious public health concern. $(3,4)$ In the past 10 years, after decades of

${ }^{*}$ Corresponding Author: Tousif Raza, Rawalpindi Medical College, Pakistan Contact No: 00923327594005, Email: tousifraza886@gmail.com

www.astesj.com

https://dx.doi.org/10.25046/aj020407 infrequent, specific outbreaks, the virus has caused major epidemic outbreaks in Africa, Asia, the India Ocean, and more recently the Caribbean and Americas. Chikungunya virus represents a substantial health burden to affected population, with symptoms that include severe joint and muscle pain, rashes, and fever, as well as prolonged periods of disability in some patients. Entry of virus into tissues causes infiltration of innate immune cells, monocytes, macrophages, neutrophils, natural killer cells and adaptive immune cells. Macrophages bearing the replicating virus, in turn, secrete pro-inflammatory cytokines IL-1B, TNF-a, IL-17. (5) Chikungunya virus (CHIKV), an arthropod-borne virus (arbovirus) that belongs to the family Togaviridae, genus Alpha 


\section{T. Raza et al. / Advances in Science, Technology and Engineering Systems Journal Vol. 2, No. 4, 51-55 (2017)}

virus.(6) Alpha viruses can be divided into New and Old World viruses. Chikungunya virus is part of the Semliki Forest SF group of Old World Alpha viruses. Chikungunya virus is a member of the arthritogenic alpha viruses, but some cases also include meningeo-encephalitis and hemorrhagic diseases too. Chikungunya and O'nyong virus have $85 \%$ similarities in their symptoms. Chikungunya virus is a small (about 60-70 nm diameter), spherical, enveloped, positive-stranded RNA virus. The chikungunya virus genome is 11,805 nucleotides long and encodes for two polyproteins. The virus consist of four nonstructural proteins and three structural proteins. (7)

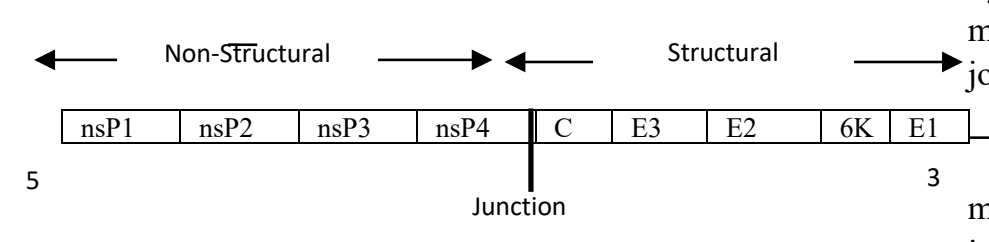

Figure 1: Chikununya virus genome structure (8)

\section{Virus Replication}

Virions located on the surface of the cell membrane enter the host cells by fusion and endocytosis of the viral envelope $(9,10)$. The uncoating of the Virions occurs in the cytoplasm. The site of mRNA transcription is in the cell cytoplasm. Replication is not restricted to a particular tissue or organs. Figure 2 shows replication as under:

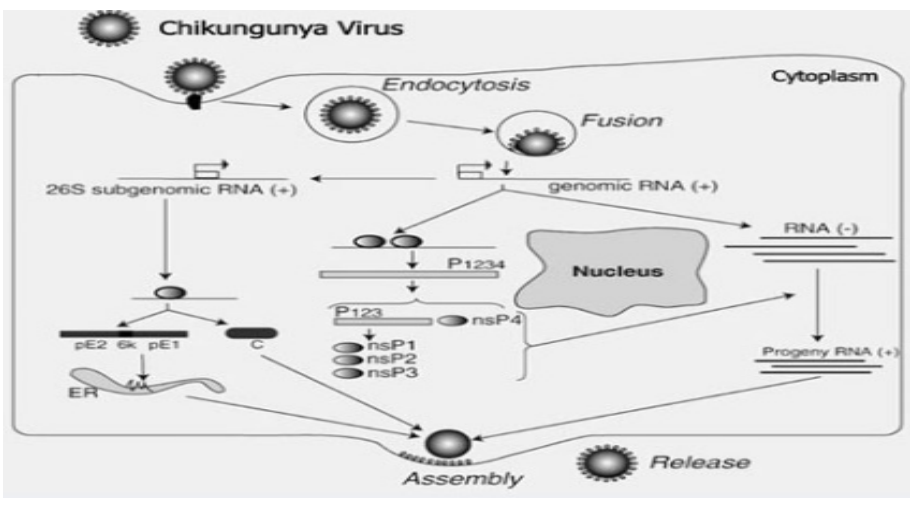

Figure 2: Replication of CHIKV (11)

\section{History:}

The disease was first detected in 1953 in Africa following an outbreak on the Makonde Plateau in a Swahili village in the Newalla district, Tanzania (12). The virus was isolated from the serum of febrile patient. The name chikungunya is derived from the Makonde word kungunyala, meaning "that which bends up" in reference to the stooped posture developed as a result of the arthritic symptoms of the disease. In Swahili, this means "the illness of the bended walker".

Chikungunya virus likely originated in the Central /East Africa (13), where the virus has been found to circulate in a sylvatic cycle between forest-dwelling mosquitoes and non-human primates.
Currently, chikungunya fever has been identified in nearly 40 countries. Recent epidemics in Indian Ocean an Americas have led to the recognition that CHIKV is capable of moving into previously unaffected areas and causing significant levels of human suffering. (14) In 2008, chikungunya was listed as a US National institute Of Allergy and Infectious Disease (NIAID)category c priority pathogen.

\section{Symptoms:}

Most of people infected with Chikungunya virus will develop some symptoms are fever and very debilitating joint pain. Symptoms usually begin 3-7 days after being bitten by infected mosquito. Other symptoms may include headache, muscle pain, joint swelling, or rash. Chikungunya disease does not often results in death, but the symptoms can be severe and disabling. Most patients feel better within a week. In some people, the joint pain may persist for months. People at risk for more severe disease include newborns infected around the time of birth, older adults ( $>60$ years), and people with medical conditions such as high blood pressure, diabetes, or heart disease. Once a person has been infected, he or she is likely to be protected from future infections

\section{Diagnostic techniques:}

Several methods can be used for diagnosis.

1. Enzyme-linked immunosorbent assays (ELISA), Serologic tests may confirm the presence of $\operatorname{IgM}$ and $\operatorname{IgG}$ anti-chikungunya antibodies. An IgM antibody level is highest 3 to 5 weeks after the onset of illness and persists for about 2 months. Samples collected during the first week after the onset of symptoms should be tested by both serological and virological methods (RT-PCR). $(15,16)$

2. Reverse transcription-polymerase chain reaction (RT-PCR) methods are available but are of variable sensitivity. RT-PCR products from clinical samples may also be uses for genotyping of the virus, allowing comparisons with virus samples from various geographical sources. (17)

3. Immunofluorescence assays are sensitive and specific but lack the ability to quantify antibodies, are subjective, and require specific equipment and training. (18)

4. Plaque reduction neutralization tests (PRNT) are very useful because they are quite specific for alpha viruses and are gold standard for confirmation of serological test results, however it require live virus and special laboratory containment equipments. (19)

5. Haemagglutination-inhibition test used to diagnose disease by distinguishing chikungunya strain. Chikungunya is confirmed when symptoms such as fever and joint pain seen along with four fold Haemagglutination Inhibition antibody difference in 
T. Raza et al. / Advances in Science, Technology and Engineering Systems Journal Vol. 2, No. 4, 51-55 (2017)

paired serum samples. This turns positive within 5 to 8 days of infection. $(20,21)$

6. POC (Point-Of-Care) Assays has been recommended to facilitate outbreak control. Rapid CHIKV IgM POC tests are now available, but little information exists regarding their performance. (22) Diagnosis of such cases require discrimination between CHIKV, Dengue and Zika Virus, this could be facilitated by use of reliable POC Assay. POC tests are highly cost-effective because they are easy to perform.

\section{Vaccine Research:}

A phase 2 clinical vaccine trial sponsored by the US Government in 2000, used a live, attenuated virus, developing viral resistance in $98 \%$ of those tested after 28 days and $85 \%$ still showed resistance after one year.(10) However, live chikungunya vaccines are still questionable as there could be a risk of a live vaccine possibly inducing chronic rheumatism.(23)

DNA vaccination is a technique for protecting an organism against disease by injecting it with genetically engineered DNA to produce an immunological response. Nucleic acid vaccines are still experimental. DNA vaccines have advantages over conventional vaccines as they have ability to induce a wider range of immune response types.

The recent vaccine cassette was designed based on chikungunya virus capsid and Envelop specific consensus sequences with several modifications, including codon optimization, RNA optimization, the addition of a Kozak sequence, and a substituted immunoglobin E leader sequence. These results support further study of the use of consensus CHIKV antigen in a potential vaccine cocktail.

Insecticide susceptibility status and major detoxifying enzymes activities in Aedes Albopictus (Skuse), Vector of dengue and Chikungunya in Northern part of West Bengal, India $27 \mathrm{Feb}$ 2017.(10) Vector control with the use of insecticides remains the suitable method of choice to stop the transmission of these diseases.

\section{Clinical Manifestations:}

\section{Rheumatic manifestations associated with Chikungunya virus infection:}

A study of 307 patients with 32 month follow-up done on 2017 Feb 23. A Cohort of 307 patients underwent rheumatologic examinations for pain secondary to Chikungunya virus infection. The long term evaluation was conducted by telephone survey 1 and 2 years after the onset of the viral infection. At inclusion, mean age was 54 years (24-87) and $83.1 \%$ of the patients were female. Chronic joint pain was associated with synovitis in $64.2 \%$ of the patients, affecting primarily the wrists, the proximal interphalangeal joints of the fingers, and ankles.(24) Attempts to detect viral genome in joint fluid (10 patients) and synovial tissue
(6 patients) using the RT-PCR technique were repeatedly unsuccessful. With a mean follow-up of 32 months, joint pain persisted in $83.1 \%$ of the patients. Functional impairment, however, was moderate, with a HAQ score of 0.44+/- 0.5.

\section{Acute Respiratory Distress Syndrome,}

An unusual case with all other symptoms of Chikungunya virus infection showed bilateral infiltrates involving all zones with normal cardiac size with no evidence of pleural effusion suggestive of ARDS. (25) The working diagnosis of mild ARDS as per Berlin criteria secondary to Chikungunya infection was established with baseline Acute Physiology and Chronic Health Evaluation score of 14

\section{Cutaneous manifestations:}

Individuals with CHIKV fever frequently present with flushed appearance involving the face and trunk, followed by a diffuse erythematous maculopapular rash of the trunk and extremities, sometimes involving the palms and soles.(26) The rash gradually fades; may evolve into petechiae, urticaria, xerosis, or hypermelanosis; or resolve with desquamation. $(18,19)$

\section{Neurological manifestation:}

In the acute phase of illness (reported during the outbreak in Indian Ocean in 2005-2006), 23 patients presented with neurological symptoms associated with abnormal CSF tests and positive CSF immunoglobulin M (IgM) or reverse-transcriptase polymerase chain reaction(RT-PCR) for Chikungunya virus.(27) Clinical manifestations in this outbreak included altered mental status or behavior in $95 \%$, headache in $30.4 \%$, seizures in $26 \%$, motor dysfunction in $4.3 \%$, and sensorineural abnormalities in $8.7 \%$.

\section{Outbreak of Chikungunya in Pakistan:}

Chikungunya virus was found as early as 1983(28). In fact, a fewer patients with chikungunya were also reported in Lahore during the 2011 dengue outbreak(29). The current outbreak(30) is said to have started on the second week of December, 2016. Different health-care authorities in Karachi estimated the total number of patients to be more than 30,000. The National Institutes of Health, Pakistan, and Armed Forces Institute of Pathology, Pakistan, have so for confirmed more than 4000 cases through qualitative RT-PCR. Ministry of Health Services, Regulation and Coordination (NHSRC) has for the first time on 26 December officially reported the outbreak to the World Health Organization (WHO).

"It is for the first time that Pakistan has officially documented the cases and has reported to WHO. The disease surfaced after some patients suffering from high fever and joint pain were taken to the facility. Pakistan undergoing substantial climate changes. The rising temperature has nurtured the outbreak of many arboviral illnesses in the region, including malaria and dengue. The deplorable sanitary conditions of most Asian countries 


\section{T. Raza et al. / Advances in Science, Technology and Engineering Systems Journal Vol. 2, No. 4, 51-55 (2017)}

further adds fuel to the fire by providing excellent breeding grounds for arthropod vectors. Chikungunya is now spreading explosively in Karachi, Pakistan. Many patients develop neurological, cardiovascular, pulmonary, renal, ocular, and cutaneous sequelae following acute infection (31). Open sewers and feculent morasses, which are excellent breeding habitats for mosquitoes, can be found all throughout the city(29). There is an urgent need to get rid of the city of stagnant water bodies and to raise awareness via campaigns.

\section{Prevention and Control:}

The proximity of mosquito vector breeding sites to human habitation is a risk factor for chikungunya as well as for other diseases. Prevention and control relies heavily on reducing the number of natural and artificial water-filled containers habitats that support breeding of the mosquitoes. During outbreaks, clothing which minimizes skin exposure to the daybiting vectors is advised. Repellants can be applied to exposed skin, Insectide-treated mosquito nets for children, or sick or older afford good protection. Mosquito coils or other insecticide vaporizers may also reduce indoor biting.(32)

Basic precautions should be taken by people travelling to risk areas and these include use of repellents, wearing long sleeves and pants and ensuring rooms after fitted with screens to prevent mosquitoes from entering.

There is no specific antiviral drug treatment for chikungunya. It has now been shown that type1 Interferon sensing by non-myeloid cells plays a significant role in fighting against Chikungunya infection. Treatment is directed primarily at relieving the symptoms, including the joint pain using antipyretic, optimal analgesics and fluids. There is no commercial chikungunya vaccine.

\section{Conclusion:}

Chikungunya leads to (self-perceived) long term sequelae in a considerable proportion of the patients, impacting significantly on quality of life(33). Long-term chikungunya sequelae must be taken into account when dealing with this disease because of its important effects on public and individual health. Prospective large scale, long-term studies with objective assessment of signs and symptoms attributed to the disease are needed to optimally quantify and qualify these problems.

\section{Recommendations:}

Following recommendations can be helpful in vector control and its transmission.

1. Advocacy, social mobilization, regulatory control for public health and empowerment of communities.

2. Collaboration within the health sector and with other sectors through the optimal use of resources, planning, monitoring and decision making.
3. Integration of non-chemical and chemical vector control methods and integration with other disease control measures.

4. Evidence-based decision making guided by operational research and entomological and epidemiological surveillance and evaluation.

5. Development of adequate human resources, training and career structures at national and local level to promote capacity building and manage Integrated Vector Management (IVM).

\section{Conflict of Interest}

The authors declare no conflict of interest.

\section{Acknowledgment}

Special thanks to Prof. Shoaib Shafi and Dr. Nadeem Ikram from Benazir Bhutto Hospital, Rawalpindi for kind guidance and support. We also thank to Dr. Usman Waheed from Safe Blood Transfusion Program, Pakistan for kind guidance during review work.

\section{References}

[1] Receveur M, Ezzedine K, Pistone T, Malvy D. Chikungunya infection in a French traveller returning from the Maldives, October, 2009. Euro surveillance : bulletin Europeen sur les maladies transmissibles $=$ European communicable disease bulletin. 2010 Feb 25;15(8):19494. PubMed PMID: 20197023. Epub 2010/03/04. eng.

[2] Heywood AE, Zwar N, Forssman BL, Seale H, Stephens N, Musto J, et al. The contribution of travellers visiting friends and relatives to notified infectious diseases in Australia: state-based enhanced surveillance. Epidemiology and infection. 2016 Aug 30:1-10. PubMed PMID: 27574034. Pubmed Central PMCID: PMC5111124. Epub 2016/08/31. eng.

[3] Weibel Galluzzo C, Kaiser L, Chappuis F. [Reemergence of Chikungunya virus]. Revue medicale suisse. 2015 May 06;11(473):1012, 4-6. PubMed PMID: 26103764. Epub 2015/06/25. Chikungunya: La reemergence. fre.

[4] Weaver SC, Forrester NL. Chikungunya: Evolutionary history and recent epidemic spread. Antiviral Res. 2015 Aug;120:32-9. PubMed PMID: 25979669. Epub 2015/05/17. eng.

[5] Mathew AJ, Ganapati A, Kabeerdoss J, Nair A, Gupta N, Chebbi P, et al. Chikungunya Infection: a Global Public Health Menace. Current allergy and asthma reports. 2017 Feb;17(2):13. PubMed PMID: 28233156. Epub 2017/02/25. eng.

[6] Lo Presti A, Cella E, Angeletti S, Ciccozzi M. Molecular epidemiology, evolution and phylogeny of Chikungunya virus: An updating review. Infection, genetics and evolution : journal of molecular epidemiology and evolutionary genetics in infectious diseases. $2016 \mathrm{Jul} ; 41: 270-8$. PubMed PMID: 27085290. Epub 2016/04/18. eng.

[7] Weaver SCL, Marc. Chikungunya Virus and Global Spread of a MosquitoBorne Disease. New England Journal of Medicine. 2015;372(13):1231-9. Pubmed Central PMCID: 25806915.

[8] Pietila MK, Hellstrom K, Ahola T. Alphavirus polymerase and RNA replication. Virus research. 2017 Jan 16. PubMed PMID: 28104453. Epub 2017/01/21. eng.

[9] Silva LA, Dermody TS. Chikungunya virus: epidemiology, replication, disease mechanisms, and prospective intervention strategies. The Journal of clinical investigation. 2017 Mar 01;127(3):737-49. PubMed PMID: 28248203. Pubmed Central PMCID: PMC5330729. Epub 2017/03/02. eng.

[10] JCI Silva LD. TS Chikungunya virus. The Journal of clinical investigation. 201701 March;127(3):737-49. 


\section{T. Raza et al. / Advances in Science, Technology and Engineering Systems Journal Vol. 2, No. 4, 51-55 (2017)}

[11] Maxime Soligant BG, Stephen Higgs. Replication cycle of chikungunya: A re-emerging arbovirus. Virology. 2009;2(393):183-97. Pubmed Central PMCID: PMC2915564.

[12] Zeller H, Van Bortel W, Sudre B. Chikungunya: Its History in Africa and Asia and Its Spread to New Regions in 2013-2014. The Journal of infectious diseases. 2016 Dec 15;214(suppl 5):S436-S40. PubMed PMID: 27920169. Epub 2016/12/07. eng.

[13] Wahid B, Ali A, Rafique S, Idrees M. Global expansion of chikungunya virus: mapping the 64-year history. Int J Infect Dis. 2017 Mar 10. PubMed PMID: 28288924 .

[14] Morrison CR, Plante KS, Heise MT. Chikungunya Virus: Current Perspectives on a Reemerging Virus. Microbiology spectrum. 2016 Jun;4(3). PubMed PMID: 27337473. Epub 2016/06/24. eng.

[15] Fortuna C, Remoli ME, Rizzo C, Benedetti E, Fiorentini C, Bella A, et al. Imported arboviral infections in Italy, July 2014-October 2015: a National Reference Laboratory report. BMC infectious diseases. 2017 Mar 16;17(1):216. PubMed PMID: 28302072. Pubmed Central PMCID: PMC5356298. Epub 2017/03/18. eng.

[16] Gaibani P, Landini MP, Sambri V. Diagnostic Methods for CHIKV Based on Serological Tools. Methods in molecular biology (Clifton, NJ). 2016;1426:63-73. PubMed PMID: 27233261. Epub 2016/05/29. eng.

[17] Cabral-Castro MJ, Cavalcanti MG, Peralta RH, Peralta JM. Molecular and serological techniques to detect co-circulation of DENV, ZIKV and CHIKV in suspected dengue-like syndrome patients. Journal of clinical virology : the official publication of the Pan American Society for Clinical Virology. 2016 Sep;82:108-11. PubMed PMID: 27479173. Epub 2016/08/02. eng.

[18] Moi ML, Takasaki T. Chikungunya Virus Growth and Fluorescent Labeling: Detection of Chikungunya Virus by Immunofluorescence Assay. Methods in molecular biology (Clifton, NJ). 2016;1426:143-52. PubMed PMID: 27233268. Epub 2016/05/29. eng.

[19] Cordeiro MT, Brito CA, Pena LJ, Castanha PM, Gil LH, Lopes KG, et al. Results of a Zika Virus (ZIKV) Immunoglobulin M-Specific Diagnostic Assay Are Highly Correlated With Detection of Neutralizing Anti-ZIKV Antibodies in Neonates With Congenital Disease. The Journal of infectious diseases. 2016 Dec 15;214(12):1897-904. PubMed PMID: 27923950. Epub 2016/12/08. eng.

[20] Widjaja S, Soekotjo W, Hartati S, Jennings GB, Corwin AL. Prevalence of hemagglutination-inhibition and neutralizing antibodies to arboviruses in horses of java. The Southeast Asian journal of tropical medicine and public health. 1995 Mar;26(1):109-13. PubMed PMID: 8525395. Epub 1995/03/01. eng.

[21] Adesina OA, Odelola HA. Ecological distribution of Chikungunya haemagglutination inhibition antibodies in human and domestic animals in Nigeria. Tropical and geographical medicine. 1991 Jul;43(3):271-5. PubMed PMID: 1667829. Epub 1991/07/01. eng.

[22] Burdino E, Calleri G, Caramello P, Ghisetti V. Unmet Needs for a Rapid Diagnosis of Chikungunya Virus Infection. Emerg Infect Dis. 2016 Oct;22(10):1837-9. PubMed PMID: 27347706. Pubmed Central PMCID: PMC5038423. Epub 2016/06/28. eng.

[23] Erasmus JH, Auguste AJ, Kaelber JT, Luo H, Rossi SL, Fenton K, et al. A chikungunya fever vaccine utilizing an insect-specific virus platform. Nature medicine. 2017 Feb;23(2):192-9. PubMed PMID: 27991917. Pubmed Central PMCID: PMC5296253. Epub 2016/12/20. eng.

[24] Lui NL, Leong HN, Thumboo J. Polyarthritis in four patients with chikungunya arthritis. Singapore medical journal. 2012 Apr;53(4):241-3. PubMed PMID: 22511045. Epub 2012/04/19. eng.

[25] Singh A. Acute Respiratory Distress Syndrome: An Unusual Presentation of Chikungunya Fever Viral Infection. Journal of global infectious diseases. 2017 Jan-Mar;9(1):33-4. PubMed PMID: 28250625. Pubmed Central PMCID: PMC5330044. Epub 2017/03/03. eng.

[26] Pakran J, George M, Riyaz N, Arakkal R, George S, Rajan U, et al. Purpuric macules with vesiculobullous lesions: a novel manifestation of Chikungunya. International journal of dermatology. 2011 Jan;50(1):61-9. PubMed PMID: 21182504. Epub 2010/12/25. eng.

[27] Singh A, Jain R. Neurological Manifestations of Chikungunya in Children. Indian Pediatr. 2017 Mar 15;54(3):249. PubMed PMID: 28361790.
[28] Darwish MA, Hoogstraal H, Roberts TJ, Ahmed IP, Omar F. A seroepidemiological survey for certain arboviruses (Togaviridae) in Pakistan. Transactions of the Royal Society of Tropical Medicine and Hygiene. 1983;77(4):442-5. PubMed PMID: 6314612. Epub 1983/01/01. eng.

[29] Rahman A, Lee, H, am\nd Khan, MA. Domestic water contamination in rapidly growing megacities of Asisa: case of Karachi, Pakistan. Environ Monit Assess. 1997;44:339-60.

[30] AT Bharati M SD. Vaccine research CHIKV [Journal Article]Acta. 2017 Feb;9(1):122-23. eng.

[31] Rajapakse S, Rodrigo C, Rajapakse A. Atypical manifestations of chikungunya infection. Transactions of the Royal Society of Tropical Medicine and Hygiene. 2010 Feb;104(2):89-96. PubMed PMID: 19716149. Epub 2009/09/01. eng.

[32] Heydari N, Larsen DA, Neira M, Beltran Ayala E, Fernandez P, Adrian J, et al. Household Dengue Prevention Interventions, Expenditures, and Barriers to Aedes aegypti Control in Machala, Ecuador. International journal of environmental research and public health. 2017 Feb 16;14(2). PubMed PMID: 28212349. Pubmed Central PMCID: PMC5334750. Epub 2017/02/18. eng.

[33] Van Aalst M, Nelen CM, Goorhuis A, Stijnis C, Grobusch MP. Long-term sequelae of chikungunya virus disease: A systematic review. Travel medicine and infectious disease. 2017 Jan - Feb;15:8-22. PubMed PMID: 28163198. Epub 2017/02/07. eng. 